\title{
Profissionalidade e profissionalismo docente, pensado e tecido na interdependência entre a gestão da escola e o professorado
}

\author{
Lins, Carla Patrícia Acioli ${ }^{1}$ \\ Leocádio, Patrícia Renata de Azevedo² \\ Santos, Marcia Cristina Xavier dos ${ }^{3}$
}

\begin{abstract}
Resumo
O debate educacional tem se intensificado no que se refere a problematização da formação e profissionalização docente, haja vista sua importância e contribuições na qualificação da educação escolar. Neste artigo, propomos refletir sobre a profissionalidade e profissionalismo docente a partir da escola, espaço no qual gestores e professores desenvolvem e vivenciam experiências relativas a suas atividades, trocam com seus pares, se relacionam e estabelecem compromisso com os alunos, com a comunidade e com a escola, e dispendem esforços para a escola cumprir sua função contribuindo dessa maneira com o desenvolvimento da profissionalidade $\mathrm{e}$ profissionalismo docente. Assim, objetivamos analisar as interdependências entre a gestão da escola e o professorado e suas relações com o desenvolvimento da profissionalidade e do profissionalismo docente. Para discutirmos as relações entre as interdependências estabelecidas entre gestão da escola, professorado e a profissionalização docente recorremos aos conceitos de figuração e interdependência de Norbert Elias e profissionalização de Bourdoncle. Entrevistamos professores e gestores do ensino fundamental de uma escola da rede pública municipal de Gravatá PE. De maneira geral os dados afirmam o movimento da gestão escolar em articular as dimensões administrativa e pedagógica ao contrário da tendência comumente observada de reduzir as "questões de gestão" à natureza, apenas, administrativa indicando movimento dos docentes que atuam na gestão na direção de maior desenvolvimento da profissionalidade e profissionalismo. Por outro lado os projetos/ programas concebidos externamente à escola emergem tensionando as interdependências entre gestão escolar e professorado tendendo o grupo na direção de práticas que podem desprofissionalizar o trabalho docente. Chamamos a atenção para as interdependências entre professorado e a Secretaria Municipal de Educação que se constituem em interdependências importantes para compreendermos o processo de profissionalização do professorado.
\end{abstract}

\footnotetext{
${ }^{1}$ Doutora em Sociologia. Professora da Licenciatura em Pedagogia e do Programa de Pós Graduação em Educação Contemporânea da Universidade Federal de Pernambuco - UFPE / Campus Agreste - CAA. Líder do Grupo de Pesquisa Discursos e Práticas Educacionais, Caruaru/PE. E-mail: aciolilins.carla@gmail.com

2 Graduanda em Pedagogia da Universidade Federal de Pernambuco - UFPE / Campus Agreste - CAA. Integrante do Grupo de Pesquisa Discursos e Práticas Educacionais, Caruaru/PE. E-mail: patyleocadio@hotmail.com

${ }^{3}$ Mestranda em Educação do Programa de Pós-Graduação em Educação Contemporânea da Universidade Federal de Pernambuco - UFPE / Campus Agreste - CAA. Integrante do Grupo de Pesquisa Discursos e Práticas Educacionais, Caruaru/PE. E-mail: marciaxaviersantos19@gmail.com
} 
Profissionalidade e profissionalismo docente, pensado e tecido na interdependência entre a gestão da escola e o professorado

Interdependências, Profissionalismo, Profissionalidade Docente.

\section{Abstracto}

El debate educacional se ha intensificado en lo que se refiere a la problematización de la formación y profesionalización docente, dada su importancia y contribuciones en la calificación de la educación escolar. En este trabajo, proponemos reflexionar sobre la profesionalidad y el profesionalismo docente desde la escuela, espacio en lo cual los administradores y maestros desarrollan y experimentan experiencias relacionadas a sus actividades, cambian con sus pares, interactuan y establecen compromiso con los alumnos, con la comunidad y con la escuela, y gastan esfuerzos para la escuela cumplir con su papel y contribuir con el desarrollo de la profesionalidad y profesionalismo docente. Por lo tanto, objetivamos analizar las interdependencias entre la gestión de la escuela, del los maestros y sus relaciones con el desarrollo de la profesionalidad y del profesionalismo docente. Para discutir las relaciones entre las interdependencias que se establecen entre la gestión de la escuela, los maestros y la profesionalización docente utilizamos los conceptos de figuración y interdependencia de Norbert Elias y profesionalización de Bourdoncle. Entrevistamo los maestros y administradores de la educación primaria en una escuela de la red pública municipal de Gravatá - PE. De manera general, los datos demuestran que el movimiento de la gestión escolar para articular las dimensiones administrativas y pedagógicas al revés de la tendencia observada comúnmente para reducir las "cuestiones de gestión" a un movimiento administrativo indicando movimiento de los profesores hacia la profesionalidad y el profesionalismo. Por otro lado los proyectos/programas diseñados externamente a la escuela emergen tensando las interdependencias entre la gestión de la escuela y los profesores llevando el grupo hacia prácticas que pueden desprofissionalizar el trabajo docente. Llamamos la atención sobre las interdependencias entre los maestros y el Departamento Municipal de Educación que se constituyen em interdependencias importantes para comprendernos el proceso de profesionalización de los maestros.

Interdependencias, Profesionalismo, Profesionalidad Docente.

\section{Introdução}

A partir de estudos anteriores observamos que o debate que enfoca a formação e profissionalização de professores trazem uma discussão recorrente a partir dos anos 1990, buscando problematizar os efeitos da política neoliberal, especialmente da cultura do desempenho, nas políticas educacionais e de formação de professores bem como no processo de profissionalização do professorado. Ao apontar para os desdobramentos do neoliberalismo como elemento importante a ser considerado para se compreender o processo de 
profissionalização docente, os estudos indicam que o movimento predominante do professorado, a partir da adoção de políticas de cunho neoliberal se dá geralmente na direção da desprofissionalização, precarização e proletarização da profissão, seguem nessa direção os estudos de SHIROMA e EVANGELISTA (2007); LÜDKE e BOING(2004); BALL (2004;2005) ; GARCIA e ANADON (2009), dentre outros. Sem desconhecer a importância desse debate para a compreensão sobre formação e profissionalização docente, propomos neste artigo 4 refletir sobre a profissionalidade e profissionalismo docente a partir da escola, espaço no qual gestores e professores desenvolvem e vivenciam experiências relativas a suas atividades, trocam com seus pares, se relacionam e estabelecem compromisso com os alunos, com a comunidade e com a escola, e dispendem esforços para a escola cumprir sua função construindo dessa maneira sentidos e significados sobre a profissão docente. Assim, neste artigo apresentamos os achados de pesquisa acerca das interdependências entre a gestão da escola e o professorado e suas relações com o desenvolvimento da profissionalidade e profissionalismo docente.

Para discutirmos as relações entre as interdependências estabelecidas entre gestão da escola, professorado e a profissionalização docente recorremos aos conceitos de figuração e interdependência de Norbert Elias e ao conceito de profissionalização proposto por Bourdoncle (1991). Esclarecemos que de acordo com Elias o conceito de figuração é definido como uma "rede de interdependências formadas entre seres humanos e que os liga, ou seja: uma estrutura de pessoas mutuamente orientadas e dependentes" (ELIAS, 1990, p. 249). Não importa se elas são formadas por dois ou mais indivíduos; ao estabelecerem interdependências eles formam figurações sociais específicas, por exemplo, a família, uma comunidade, a escola, a profissão ou o Estado. Longe de serem homogêneas, as figurações podem se apresentar a partir de diversas características, quer dizer, possuir maior ou menor harmonia, ser mais

\footnotetext{
${ }^{4}$ Este artigo se constitui em recorte da pesquisa intitulada Profissionalização docente: interdependências entre a gestão escolar e o professorado do ensino fundamental - o caso do município de Gravatá - PIBIC/ UFPE 2014-2015 que por sua vez é desdobramento de pesquisas desenvolvidas anteriormente sobre processos de profissionalização docente.
} 
ou menos duradouras, efêmeras, serem mais ou menos estáveis, mais ou menos tensas, se compor de dois, de vários ou de inúmeros indivíduos e de grupos, ser grande ou pequena (QUINTANEIRO, 2010). Há apenas a ser considerado como presença constante a existência de interdependências. Por isso, consideramos que a equipe gestora e os professores são figurações que estabelecem interdependências ao compartilharem questões comuns como por exemplo processos de ensinar e aprender.

É importante lembrar que a sociologia figuracional proposta por Elias não se detém na análise de condutas individuais ou de estruturas externas a elas de maneira isolada mas, se concentra na compreensão das redes construídas por sujeitos ligados uns aos outros e no conjunto não homogêneo de posições sociais que podem se apresentar mais ou menos complexas, formadas por pessoas ou grupos em interdependências, sem deixar de lado os reflexos sobre as ações dos indivíduos, de seus sentimentos, e pensamentos.

\section{As interdependências entre gestão escolar e docentes: profissionalidade e profissionalismo}

Observamos que as interdependências estabelecidas por professores entre si e com os outros grupos na escola são marcadas, predominantemente, pela natureza de sua tarefa: ensinar - aprender. Muito da movimentação dos grupos e seus sujeitos no interior da escola percorre a realização dessa tarefa. Nesse sentido, destacamos que o simples reconhecimento e predominância do ensino nos vínculos estabelecidos entre professores, e entre professores e gestão, professores e alunos, e professores e comunidade não significa, necessariamente, que as interdependências entre essas figurações movimentem o professorado na direção da profissionalização, justamente, porque as interdependências são repletas de tensões, disputas de poder e interesses entre os grupos e sujeitos, e dessa maneira podem pressionar o professorado tanto no sentido da profissionalização quanto em seu contrário. Dessa forma, salientamos que traçar os movimentos dos grupos em relação uns aos outros e identificar o que e como se tornam interdependentes é importante na busca de compreender a diversidade de questões que entram em jogo no 
processo de profissionalização docente.

Dito o que estamos tomando por figurações e interdependências, esclarecemos o conceito de profissionalização e suas dimensões profissionalidade, profissionalismo e profissionismo, para tal apoiamo-nos em Bourdoncle (1991). Segundo o autor a profissionalização se constitui no processo pelo qual uma ocupação passa, a fim de ser reconhecida como uma profissão. Bourdoncle entende a profissionalização como processo, apontando a existência de três estados, são eles: profissionalidade, profissionismo e profissionalismo. O profissionalismo faz referência ao processo de adesão ao discurso e às normas, à consciência e às exigências profissionais que são estabelecidas coletivamente. O processo que conduz ao profissionalismo é a socialização profissional. Nesse mesmo sentido encontramos a definição dada por Freidson (2009) para quem "o profissionalismo é um conjunto de atitudes que os membros de uma profissão desenvolvem em relação ao trabalho" (p. 210).

A profissionalidade é definida como natureza elevada e racional dos saberes bem como a competência para utiliza-los no exercício profissional. Essas capacidades são desenvolvidas através da ação dos especialistas e da formação contínua promovendo o aperfeiçoamento das competências e a utilização de saberes racionais no exercício da profissão, possibilitando maior eficácia coletiva e individual. Por fim o profissionismo refere-se às estratégias e discursos utilizados pelo grupo profissional para reivindicar o reconhecimento de suas atividades. Ou seja, diz respeito, ao processo de aperfeiçoamento coletivo do status social da atividade, exemplificando-o com a ação dos sindicatos e associações. Ancorados nos conceitos apresentados, expomos o percurso metodológico trilhado para compreender as interdependências entre a gestão da escola e o professorado e suas relações com a profissionalidade docente.

Ao partirmos do pressuposto de que a gestão da escola estabelece interdependências com o professorado, integrou o grupo pesquisado professores e equipe gestora de uma escola da rede pública municipal de Gravatá - PE. Não especificamos critérios para escolhermos os professores que 
colaboraram com a pesquisa, bastou que estivessem vinculados à rede de ensino municipal. Os dados foram construídos a partir da realização de entrevistas semi-estruturadas com integrantes da equipe gestora e professoras ${ }^{5}$, de observações do contexto escolar e de um questionário sócio profissional.

O roteiro de entrevista se organizou não só a partir da literatura que fundamenta o estudo, mas também foi subsidiado pelas demandas que emergiram das observações do campo. Utilizamos também um questionário para reunirmos dados sócio profissionais dos participantes do grupo pesquisado. Para dar sentido aos dados e realizarmos a análise nos orientamos a priori pelos conceitos de interdependência, processo, figuração e profissionalização, profissionalidade e profissionalismo observando os movimentos no interior das figurações e entre elas, como indicado por Elias, podendo dessa forma identificar quem configura com quem, como, e por que.

A partir do questionário pudemos traçar um perfil dos gestores e professores que colaboraram com a pesquisa. A gestora e a vice gestora possuem a graduação em Pedagogia e concluíram a graduação, respectivamente, nos anos de 2006 e 2004. Ambas concluíram o curso de especialização nos anos de 2006 e 2007. A gestora possui especialização em Gestão Escolar e Coordenação Pedagógica está na rede municipal há quinze anos, segundo ela entrou no quadro de efetivos por concurso público. Na função está há oito anos e há três anos é gestora da escola. Já a vice gestora está na rede há vinte e três anos e apenas há dois anos está na função e na escola. Ela nos informou que o acesso a rede municipal foi por concurso público. A professora 1 está na rede há nove anos e na escola há seis meses é graduada em Letras e possui especialização em Metodologia em Línguas, seu vínculo com a rede de ensino municipal é estabelecido por contrato de trabalho. A professora 2 é efetiva, está na rede há 21 anos e há três anos trabalha nessa escola. É graduada em Letras com especialização em Língua Portuguesa e atualmente cursa mestrado em Ciências da Educação com previsão de conclui-lo em 2016.

\footnotetext{
${ }^{5} \mathrm{O}$ quadro de docentes não possuía nenhum professor, dessa forma utilizaremos ao longo do texto apenas professora
} 
Atualmente, a escola atende estudantes do Ensino Fundamental II e da Educação de Jovens e Adultos funcionando nos turnos da manhã, tarde e noite. Apesar de pequeno, o espaço físico, dentro das possibilidades, é bem organizado. Ao lidar com o espaço da escola a gestora sinaliza que compreende que suas decisões e encaminhamentos de natureza administrativa repercutem e garantem o trabalho pedagógico mais qualificado, tivemos como exemplo o uso do espaço coberto que a escola dispõe para recreação. A gestora se preocupou em organizar a sua utilização para que todos pudessem dispor do espaço, ou seja, não optou por deixa-lo ocioso como muitas vezes pudemos observar bibliotecas e/ou laboratórios sem utilização ou subutilizados porque não há uma organização para que os mesmos possam funcionar de acordo com as demandas pedagógicas e educativas dos estudantes.

Neste caso, destacamos que a gestora ao se envolver de maneira articulada com as dimensões administrativa e pedagógica parece apontar sua adesão à docência - traços do profissionalismo - bem como possibilitar que os professores possam também desenvolver o sentimento de pertença a um grupo profissional e sobretudo, compromisso com a aprendizagem de seus alunos e com a escola, ou seja, as interdependências entre a equipe gestora e os professores, apesar de ter momentos contrários ao movimento de profissionalização, também aponta em seu sentido.

As entrevistas reafirmam o recente movimento da gestão escolar em se preocupar com a articulação entre a dimensão administrativa e pedagógica, atividades consideradas próprias da gestão mas geralmente tratadas como se fossem distintas e não tivessem qualquer relação entre si. $O$ trabalho na escola é compartilhado entre equipe gestora e professores ao contrário da tendência observada nas práticas de gestão escolar de reduzir as "questões de gestão" à natureza burocrática e administrativa pois o gestor acaba se envolvendo com questões dessa ordem e secundariza suas atividades de natureza pedagógica junto aos professores e alunos.

Considerando que a escola é um espaço socialmente reconhecido como local de ensino e aprendizagem os dados sinalizam para o envolvimento da 
equipe gestora com os processos de ensinar e aprender se configurando no estabelecimento de interdependências entre gestão e professorado. Vemos que as interdependências que se estabelecem entre professorado e gestão pode contribuir com o movimento do professorado na direção da profissionalização uma vez que a gestão realiza ações que favorecem ao professorado desenvolver, incorporar e compartilhar práticas pautadas numa expertise própria à docência .

Nesse sentido as interdependências entre gestão e professorado, trabalho administrativo e pedagógico pode ser ilustrado a partir do extrato de fala da G 1 que aponta para a tendência de articulação das duas dimensões quando descreve como desenvolve seu trabalho na escola: "Junto aos professores a gente faz o trabalho pedagógico, não só de elaboração de plano de ação, de planejamento, de observações de cadernetas, também algumas dificuldades que eles encontram". E a fala da G2 que também segue na mesma direção, diz ela: "A gente trabalha pra melhorar o ensino juntamente com o professor...". O envolvimento da gestão com o trabalho do professorado é confirmado pela professora entrevistada, diz ela "Olha o trabalho aqui é em conjunto. A gente tem assistência das coordenadoras, das gestoras...A gente tem assistência... Os pais têm acesso à escola, tem acesso a gente, tem acesso aos diretores, fazem reuniões pedagógicas... Convidam a família para a escola. Atentamos que ao articular trabalho administrativo e pedagógico a gestão sinaliza para o entendimento de que atender ao professorado, dar a ele suporte para desenvolver suas atividades implica em estar atento também aos alunos e seus pais. Nessa perspectiva as interdependências entre a equipe gestora e os professores abrem espaço favorável ao desenvolvimento da profissionalidade e do profissionalismo docente na medida em que o movimento das interdependências sugere a criação de maior compromisso com os estudantes e com a escola assim como com o ensino.

Os projetos/ programas ${ }^{6}$ desenvolvidos pelas escolas mas que não são

\footnotetext{
${ }^{6}$ Estamos nos referindo a projetos / programas concebidos externamente à escola e que tem adesão das secretarias de educação para serem desenvolvidos nas escolas da rede a exemplo do Projeto Mais Educação e Alfa e Beto.
} 
concebidos pelos professores da rede, apontam que esses tencionam as relações estabelecidas entre os gestores e professores marcando as interdependências entre esses grupos, uma vez que apesar de se apresentarem como apoio ao trabalho escolar, na prática parecem ir além disso.

Concebidos externamente às escolas, desconsiderando as especificidades e particularidades da organização e práticas docentes, os projetos e programas desenvolvidos no contexto escolar acabam ordenando a organização e utilização do tempo, do espaço, bem como grande parte das atividades do professorado porque, por exemplo, as atividades pedagógicas desenvolvidas na escola passam a se organizar em torno de exigências que visam atingir os resultados estabelecidos pelos objetivos dos projetos e /ou programas. Assim, práticas de monitoramento do trabalho desenvolvido pelo professorado, e o sentimento dos professores de obrigação de cumprir o proposto pelos projetos e/ou programas, inclusive as atividades sugeridas pelos mesmos, sinaliza para a existência de movimento nas interdependências entre gestão escolar e professores, de tendências contrárias à profissionalização na medida em que se demanda dos professores o desenvolvimento de ações e práticas que se focam nos objetivos dos projetos / programas em curso nas escolas, ou seja, decisões e intervenções tanto da gestão quanto de professores parece ser tomadas pautando-se nas demandas de resultados, prioritariamente, postas pelos projetos e/ou programas e não nas necessidades especificas aos processos de ensinar e aprender que envolvem os estudantes e professores sem considerar, muitas vezes, o projeto político pedagógico da escola.

Dessa forma, os projetos e/ou programas adotados pela secretaria de educação municipal emergem como elemento importante nas relações de interdependências estabelecidas não só entre professorado e equipe gestora mas também para as interdependências entre a secretaria de educação e os docentes, reafirmando a importância de compreensão do processo de profissionalização docente considerando a rede de interdependências que o grupo profissional se enreda.

No caso da escola pesquisada, vimos que "a adesão" aos projetos 
adotados pela secretaria de educação é marcada pela utilização de táticas. Diante "dos pacotes prontos" a gestora utiliza de uma tática "meio termo" acata os projetos encaminhados para a escola via Secretaria de Educação porém tenta junto aos professores fazer uma "adaptação a realidade da escola" segundo a G1. Entendemos que o movimento da G1 e G2 nesse sentido traz a tentativa de reconhecer a expertise e autonomia dos professores para decidirem e encaminharem os processos de ensino e aprendizagem, embora na prática sua intenção não se materializa pois os projetos acabam executados tal como pensados.

O que também chama a atenção no processo de profissionalização docente é que como os projetos e programas se constituem externamente à profissão, exercem pressão sobre o grupo, via monitoramento, avaliações e diagnósticos, produção de material didático e etc, se constituindo em tensões exercendo pressões sobre o processo de profissionalização do professorado, na direção do enfraquecimento desse processo, pois este nem ao menos é reconhecido e chamado a ocupar um lugar no debate e processo decisório no qual se define a adesão do estado, município ou escola a determinado programa e lou projeto que passam a integrar o cotidiano das redes de ensino. Notamos que a adoção aos programas e /ou projetos possuem propostas contrárias ao processo de profissionalização uma vez que o professorado recebem na escola " tudo pronto" e o seu papel na maioria das vezes acaba se reduzindo a simplesmente operacionalizar uma proposta da qual não participou de sua concepção nem foi consultado sobre a sua adesão a exemplo do programa de alfabetização Alfa e Beto adotado por muitos municípios da região Agreste apesar das críticas recebidas pelo professorado e pelo campo acadêmico.

A participação do professor na condução desses projetos acaba assumindo papel de transmissão de conteúdos, de "tarefeiro", e não de criação e autoria de suas atividades. Nessa configuração a expertise pode ficar vulnerável e acabar com seu reconhecimento enfraquecido colocando o professorado na direção contrária a sua profissionalização. Neste sentido, pensamos que o comportamento das escolas em relação a esses programas 
pode indicar desprofissionalização e precarização do trabalho docente já que um dos requerimentos à profissionalização, segundo Freidson (2009) é a proteção da expertise, que neste caso pode se tornar vulnerável, uma vez que o professorado é tanto afastado dos processos nos quais se define e se pensa a profissão, quanto se distancia da dimensão criativa, dos conhecimentos e saberes que ancoram suas práticas. Essa tarefa passa a ser atribuída aos especialistas "de fora" da docência, àqueles que concebem os programas e projetos e que muitas vezes não são portadores de um conhecimento especializado da profissão e/ou da realidade educacional das redes de ensino ou das escolas.

Durante as observações foram recorrentes explicações para o baixo rendimento escolar, que tinham como principal fio condutor do argumento a origem social e as condições de vida dos estudantes e suas famílias. Sendo este, outro dado que assumiu significado na discussão da profissionalidade e profissionalismo docente. Nesse aspecto, pensamos que as ações de gestores e professores ao tratar de percursos de aprendizagem marcados pelo insucesso, nem sempre recorrem à experiência profissional nem ao debate que tem percorrido os conhecimentos considerados próprios da profissão, na tentativa de entender os casos de insucesso escolar dos estudantes e propor experiências que possam significar percursos escolares significativos. A G2, por exemplo, ao falar sobre a aprendizagem dos alunos e sua relação com o trabalho escolar, afirmou: Porque existe o problema do aluno que não quer mesmo. Tendo tudo isso[material], mas o aluno não quer.

Nessa perspectiva de entendimento a responsabilidade é atribuída aos alunos e suas condições de vida familiar, social e econômica. Explicação que desconsidera o papel da escola e os conhecimentos profissionais acumulados e em sistematização pelo professorado. Conhecimentos que consistem na expertise profissional, e que geralmente são adquiridos durante a formação inicial, reafirmados/ reelaborados, ressignificados e maturados durante a formação continuada e em serviço, e permitem inferências, ou seja, possibilita ao professor, se perguntar sobre o que e como fazer seus alunos aprenderem, 
ou, o que e como manter seus alunos aprendendo, ou ainda, o que fazer e como fazer para que eles aprendam mais, independentemente de sua condição e origem social. Salientamos também que esse tipo de entendimento dos professores sobre a trajetória escolar de seus alunos se distancia da compreensão da educação como um direito de todos.

O planejamento do trabalho escolar emergiu dos dados como elemento importante para entendimento das interdependências entre equipe gestora coordenação pedagógica - professoras, e professoras e seus pares por ser um espaço articulador das ações que podem ser pensadas e executadas conjuntamente, estabelecendo as trocas entre pares, no sentido da melhoria das experiências de ensinar e aprender. A organização do tempo escolar da maioria das escolas não inclui o planejamento como uma atividade de natureza formativa e colaborativa, e por isso não formaliza em seu cotidiano o tempo para a organização do planejamento. Mesmo os planejamentos de aula, na maioria das escolas, não são realizados coletivamente, cada professor faz o seu, apenas trocam/ executam o que foi planejado por outro professor, em sua aula, esvaziando de sentido uma atividade docente que requer expertise. Diante de nossas observações pensamos que nesse sentido há distanciamento da equipe gestora da importância do planejamento talvez pelas exigências de resultados por parte da secretaria e do cumprimento do calendário escolar o que aparentemente atribui um sentido técnico e burocrático ao planejamento.

\section{Considerações}

A gestão escolar, como já dito anteriormente, tem recebido desde os anos 1990 certa atenção e investimento das políticas e pesquisas educacionais por sua importância na criação de uma escola de qualidade. Daí porque, diante da preocupação com a qualidade da educação escolar ofertada pelas redes de ensino, a importância de reconhecermos a necessidade de estudos e pesquisas sobre as relações entre gestão escolar, profissionalização docente e qualidade da escola considerando não só o cotidiano das escolas mas também os diversos aspectos dos contextos social, político, cultural e econômico de suas redes de ensino. 
A partir do campo, pudemos perceber a importância das interdependências estabelecidas entre a equipe gestora e o professorado para o processo de profissionalização e melhoria da qualidade da educação escolarizada não só na medida em que professores e gestores sinalizam preocupação com a garantia do processo de ensino e aprendizagem, o que de forma geral pode indicar adesão à docência.

Chamamos a atenção para as interdependências entre o professorado e a Secretaria Municipal de Educação por se mostrar importante para compreendermos o processo de profissionalização do professorado, uma vez que suas atividades se desenvolvem em redes de interdependências, as quais a secretaria de educação também faz parte. Uma breve análise dessa configuração provoca mais do que esclarece questões, e merece ser mais aprofundada. Pensamos, por exemplo, que debruçar-se sobre essas interdependências pode melhor esclarecer as relações entre a organização federativa e os processos de profissionalização docente já que compreender uma profissão requer olha-la a partir e por dentro da sociedade na qual está inserida.

Importa assim considerar o trajeto da profissão docente tentando verificar quais aspectos da sociedade em que se insere se encontram em relação com suas lutas por reconhecimento e valorização; quais elementos pressionam 0 grupo no sentido de torná-lo profissional ou quais atuam em sentido contrário. Essas são algumas questões que emergiram dos dados e que consideramos necessárias para o debate acerca da profissionalização do professorado.

\section{Referências}

BOURDONCLE, Raymond. Artisan moral ou professionnel? La place des valleurs dans la conception de la fonction et de la formation des enseignants. Spirale. Revue de Recherche en Éducation. n. 21, 1998, p. 25-34.

. La professionnalisation des enseignants: analyses sociologiques anglaises ey américaines. Revue Française de Pedagogie. n. 94, janvier-février-mars 1991, p. 7392.

BALL, Stephen J. Performatividade, privatização e o pós-Estado do Bem-Estar.

Educação e Sociedade. Campinas, v. 25, n. 89, set.-dez. 2004.

Profissionalismo, gerencialismo e performatividade. Cadernos de Pesquisa.

São Paulo, v. 35, n. 126, set.-dez. 2005. 
. Reformar escolas/reformar professores e os terrores da performatividade.

Revista Portuguesa de Educação. Portugal: Universidade do Minho Braga, a. I, v. 15, n. 2. p. 3-23.

CHAPOULIE, Jean-Michel. Sur l'analyse sociologique des groupes professsionnels.

Révue Française de Sociologie. a. XIV, 1973, p. 86-114.

DUBAR, Claude. TRIPIER, Pierre. Sociologie des professions. La 2. edition. Paris: Armand Colin, 2005,

ELIAS, Norbert. Escritos e ensaios: estado, processo e opinião pública. vol .1, Rio de Janeiro : Jorge Zahar Editora, 2006.

. O processo civilizador: uma história dos costumes. vol. 1. Rio de

Janeiro : Jorge Zahar Editora, 1994.

. Introdução à sociologia. Lisboa: Edições 70, 2005.

ENGUITA, Mariano. A ambiguidade da docência: entre o profissionalismo e a proletarização. Teoria e Educação, Porto Alegre, n. 4: p. 41-61, 1991.

La condición del docente. Cap. 11. La escuela a examen: un análisis sociológico para educadores y otras personas interesadas. Madrid: Ediciones Pirámide, 1998. p. 183-198.

EVANGELISTA, Olinda; SHIROMA, Eneida Oto. Professor: protagonista e obstáculo da reforma. Educação e Pesquisa, São Paulo, v. 33, n. 3, p. 531-541, set.-dez. 2007.

FREIDSON, Eliot. Profissão Médica: um estudo de sociologia do conhecimento aplicado. Trad. André de Faria Pereira Neto e Kvieta Brezinova de Morais. São Paulo: Editora UNESP; Porto Alegre: Sindicato dos Médicos, 2009

GARCIA, Maria Manuela A.; ANADON, Simone Barreto. Reforma educacional, intensificação e autointensificação do trabalho docente. Educação e Sociedade, Campinas, v. 30, n. 106, p. 63-85, jan.-abr. 2009.

LESSARD, Claude. Évolution du métier d'enseignant et nouvelle regulation de l'éducation. Recherche et Formation, n. 35, 2000. p. 91-116. Paris: Institute Nacional de Recherche Pedagogiques

LINS, Carla Patrícia Acioli. "Professor não dá aula, professor desenvolve aula": mudança nas atividades docentes e o processo de profissionalização - o caso de professores do ensino médio. Recife: O autor, 2011. 296 p.. Tese (Doutorado) Orientador: Profa. Dra. Silke Weber. Universidade Federal de Pernambuco, CFCH. Programa de Pós Graduação em Sociologia. Doutorado em Sociologia, 2011.

LÜDKE, Menga; BOING, Luiz Alberto. Caminhos da profissão e profissionalidade docentes. Educação e Sociedade. V.25, n.89, Campinas, set./dez. 2004.

NÓVOA, Antônio. Para o estudo sócio-histórico da gênese e desenvolvimento da profissão docente. Teoria e Educação, 4, 109 -139p., 1991.

NÓVOA, Antônio. Os professores e a sua formação. 2. ed. Afragide, Portugal: Publicação Dom Quixote, 1992.

. Os professores na virada do milênio: do excesso dos discursos à pobreza das práticas. Educação e Pesquisa, São Paulo, v. 25, n. 1, jan.-jun. 1999.

PERRUSI, Artur. Tiranias da identidade. 2008. Tese (Doutorado em Sociologia), João Pessoa, Universidade Federal da Paraíba, 2008

QUINTANEIRO, Tania. Processo civilizador, sociedade e individuo na teoria 
sociológica de Norbert Elias. Belo Horizonte: Argumentum, 2010.

RUSSO, Miguel Henrique. Escola e paradigmas de gestão. Eccos Revista Científica, UNINOV, São Paulo, v. 6, n. 1, p. 25-42, 2006.

SHIROMA, Eneida Oto; EVANGELISTA, Olinda. A colonização da utopia nos discursos sobre profissionalização docente. Perspectiva, Florianópolis, v. 22, n. 2, p. 525-545, jul.-dez. 2009.

SANTOS, Lucíola Licínio de C. P.. Formação de professores na cultura do desempenho. Educação e Sociedade. V.25, n.89 Campinas, set./dez. 2004.

TARDIF, Maurice; LESSARD, Claude. O trabalho docente: elementos para uma teoria da docência como profissão de interações humanas. Petrópolis, RJ: Vozes, 2005

TARDIF, Maurice; LESSARD, Claude. 0 ofício de professor. Petrópolis: Vozes, 2008.

VILLA, Fernando Gil. A crise do professorado. Campinas, SP: Papirus,1998.

WEBER, Silke. O professorado e o papel da educação na sociedade. Campinas, SP: Papirus, 1996.

Profissionalização docente e políticas públicas no Brasil. Educação e Sociedade. V.24, n.85, Campinas, dez.2003.

WITTORSKI, Richard. La professionnalisation en questions. In: Questions de recherches en éducacion: action et identité. Paris: L'Harmattan, INRP, 2001. p. 3348 